\title{
Disruption of left-right axis specification in Ciona induces molecular, cellular, and functional defects in asymmetric brain structures
}

\author{
Matthew J. Kourakis', Michaela Bostwick ${ }^{2}$, Amanda Zabriskie ${ }^{3}$ and William C. Smith ${ }^{1,3^{*}}$ (1)
}

\begin{abstract}
Background: Left-right asymmetries are a common feature of metazoans and can be found in a number of organs including the nervous system. These asymmetries are particularly pronounced in the simple central nervous system (CNS) of the swimming tadpole larva of the tunicate Ciona, which displays a chordate ground plan. While common pathway elements for specifying the left/right axis are found among chordates, particularly a requirement for Nodal signaling, Ciona differs temporally from its vertebrate cousins by specifying its axis at the neurula stage, rather than at gastrula. Additionally, Ciona and other ascidians require an intact chorionic membrane for proper left-right specification. Whether such differences underlie distinct specification mechanisms between tunicates and vertebrates will require broad understanding of their influence on CNS formation. Here, we explore the consequences of disrupting left-right axis specification on Ciona larval CNS cellular anatomy, gene expression, synaptic connectivity, and behavior.

Results: We show that left-right asymmetry disruptions caused by removal of the chorion (dechorionation) are highly variable and present throughout the Ciona larval nervous system. While previous studies have documented disruptions to the conspicuously asymmetric sensory systems in the anterior brain vesicle, we document asymmetries in seemingly symmetric structures such as the posterior brain vesicle and motor ganglion. Moreover, defects caused by dechorionation include misplaced or absent neuron classes, loss of asymmetric gene expression, aberrant synaptic projections, and abnormal behaviors. In the motor ganglion, a brain structure that has been equated with the vertebrate hindbrain, we find that despite the apparent left-right symmetric distribution of interneurons and motor neurons, AMPA receptors are expressed exclusively on the left side, which equates with asymmetric swimming behaviors. We also find that within a population of dechorionated larvae, there is a small percentage with apparently normal left-right specification and approximately equal population with inverted (mirror-image) asymmetry. We present a method based on a behavioral assay for isolating these larvae. When these two classes of larvae (normal and inverted) are assessed in a light dimming assay, they display mirror-image behaviors, with normal larvae responding with counterclockwise swims, while inverted larvae respond with
\end{abstract}

\footnotetext{
* Correspondence: w smith@ucsb.edu

${ }^{1}$ Neuroscience Research Institute, University of California, Santa Barbara, CA 93106, USA

${ }^{3}$ Department of Molecular, Cell and Developmental Biology, University of California, Santa Barbara, CA 93106, USA

Full list of author information is available at the end of the article
}

(c) The Author(s). 2021 Open Access This article is licensed under a Creative Commons Attribution 4.0 International License, which permits use, sharing, adaptation, distribution and reproduction in any medium or format, as long as you give appropriate credit to the original author(s) and the source, provide a link to the Creative Commons licence, and indicate if changes were made. The images or other third party material in this article are included in the article's Creative Commons licence, unless indicated otherwise in a credit line to the material. If material is not included in the article's Creative Commons licence and your intended use is not permitted by statutory regulation or exceeds the permitted use, you will need to obtain permission directly from the copyright holder. To view a copy of this licence, visit http://creativecommons.org/licenses/by/4.0/. The Creative Commons Public Domain Dedication waiver (http://creativecommons.org/publicdomain/zero/1.0/) applies to the data made available in this article, unless otherwise stated in a credit line to the data. 
clockwise swims.

Conclusions: Our findings highlight the importance of left-right specification pathways not only for proper CNS anatomy, but also for correct synaptic connectivity and behavior.

Keywords: Left-right asymmetry, Ciona, Visuomotor behavior, AMPA receptor

\section{Background}

As sister taxa, tunicates and vertebrates each have a central nervous system (CNS) which shares important features: neurulation-the folding of dorsal ectoderm into a tube, a tripartite brain, including a midbrain/hindbrain boundary and caudal nerve cord, and migrating neural crest or crest-like cells and neurogenic placodes, both of which contribute to sensory structures [1-5]. Yet, the simple CNS of the swimming tadpole larva of the tunicate Ciona contains less than 200 neurons, a vast contrast to cell numbers in the millions or even billions for their nearest chordate relatives, the vertebrates [6]. With an electron-micrograph-derived synaptic connectome [7], and a range of quantifiable behaviors $[8,9]$, the Ciona CNS is fertile ground for researchers seeking to bridge neural circuitry and behavior. Studies have begun to shed light on the circuit logic which governs larval behaviors. Ciona larvae have two distinct visuomotor behaviors, negative phototaxis and a looming shadow response, that are mediated by separate groups of photoreceptors, the Group I and Group II clusters, respectively [10]. Both visuomotor circuits act via minimal circuits that consist of two-interneuron sequences. The photoreceptors first project to relay neurons (RNs in Fig. 1) in the posterior brain vesicle (pBV). The relay neurons in turn project to the motor ganglion (MG), where they synapse to the motor ganglion interneurons (MGINs). The MGINs then synapse to the motor neurons (MNs). Intersecting with the looming shadow response is the negative geotaxis response. The antenna cells (Fig. 1) sense the movement of the otolith pigment cell as the larva moves with respect to gravity, but the targets of the antenna cell in the $\mathrm{pBV}$, the antenna relay neurons, are inhibited by photoreceptor RNs, unless the larva sees a light dim, at which point the inhibition is released and the larva swims upwards [8].

Most tunicates, including Ciona, are broadcast spawnersand hermaphrodites. The eggs are shed into the ocean enclosed in a membrane that in Ciona is referred to as a chorion, but is more correctly called a vitelline membrane (but by convention, we will use the term "chorion"). The surface of the chorionic membrane is studded with maternal follicle cells, which may act to increase the buoyancy of the egg, while the chorionic membrane itself serves to prevent polyspermy and fertilization with self-sperm [11, 12]. After approximately $20 \mathrm{~h}$ of development [13], the newly formed
Ciona larva will hatch from the chorionic membrane and start swimming. Most experimental procedures for the Ciona egg and embryo require the chemical removal of the chorion. These procedures include in situ hybridization, most microinjection protocols, CRISPR gene editing, and the widely used electroporation method for transgenesis. Moreover, in situ hybridization in larvae also requires the earlier removal of the chorion. This is due to the presence of a group of maternal cells, known as the test cells, that occupy the space between the egg surface and the chorionic membrane. As the embryo develops, the test cells adhere to the epidermis where they contribute to the test, a cellulosecontaining sheath that encapsulates the larva $[14,15]$. The larval test impedes the efficient penetration of in situ hybridization probes and antibodies, and itself can give very high background staining. Fortunately, dechorionation removes both the chorionic membrane and the test cells, allowing for in situ hybridization of larvae. Most tunicate researchers perform dechorionation, either with trypsin or Nathioglycolate/protease-based solutions, before fertilization or, alternatively, immediately after, but before the first cleavage plane has formed [16-18].

Despite the usefulness of this procedure, there are well-documented disruptions caused by early dechorionation to the left-right asymmetry of tunicate embryos and larvae $[19,20]$. A Nodal-dependent left-right asymmetry has been observed broadly across the chordates (and deuterostomes more generally) and generates the internal asymmetry of, for example, endodermal organs and heart in vertebrates [21-23]. Ciona likewise shows internal Nodal-dependent asymmetries [24-26]. However, unlike vertebrates where asymmetric expression of downstream targets such as Pitx and Lefty are established during the gastrula stage, tunicates show a critical period for the establishment of asymmetry at the neurula to early tailbud stages [20]. Importantly, the presence of the chorionic membrane is required in tunicates up to the early tailbud stage for proper establishment of leftright asymmetry. Drugs such as proton pump inhibitors have similar effects as early dechorionation, as neurulastage embryos treated with these drugs show altered symmetry of internal organs after metamorphosis [20, 27] suggesting that the removal of the chorionic membrane may work, in part, through disruption of the ionic environment [20]. Contact between the left epidermis with the inner chorionic membrane appears to be 


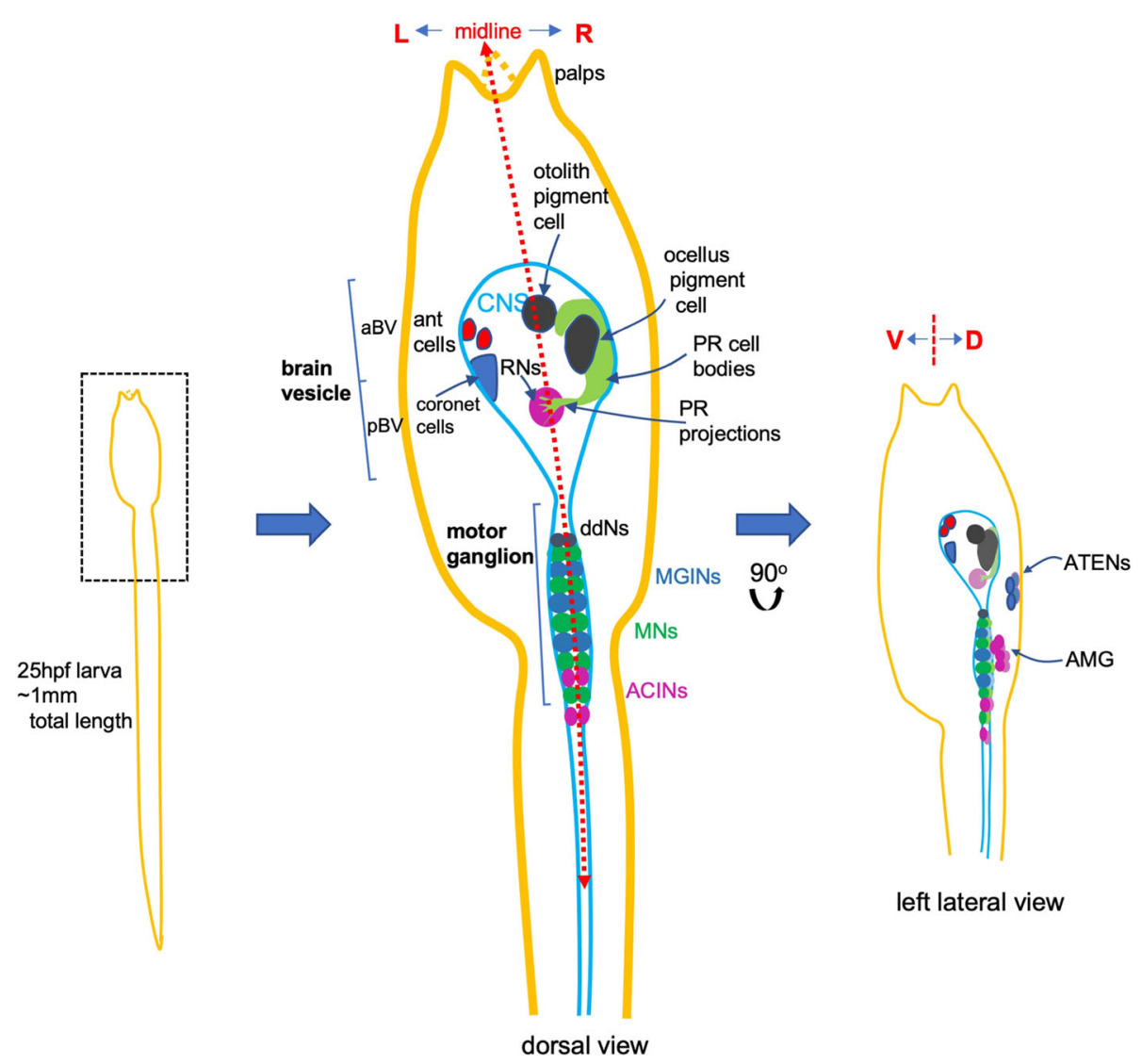

Fig. 1. Cartoons of Ciona larva depicting prominent features of CNS anatomy with emphasis on neuron groups discussed in the text. The middle detail highlights internal left-right asymmetry; the smaller detail at right shows a lateral view, adding dorsal neuron groups. Abbreviations: hpf, hours post-fertilization; ant, antenna; L, left; R, right; aBV, anterior brain vesicle; $\mathrm{pBV}$, posterior brain vesicle; PR, photoreceptor; RN, relay neuron; $\mathrm{ddN}$, descending decussating neuron; MGIN, motor ganglion interneuron; $\mathrm{MN}$, motor neuron; $\mathrm{ACIN}$, ascending contralateral inhibitory neuron; $\mathrm{V}$, ventral; D, dorsal; ATEN, anterior trunk epidermal neuron; AMG, ascending motor ganglion neuron

required for left-sided nodal expression in Halocynthia (although this may vary across ascidian species) [24, 28]. Consistent with this requirement, the application of pressure so that both left and right epidermis contact the chorion results in bilateral nodal expression. Among the structures with left-right asymmetry in Ciona, the larval CNS is particularly pronounced [7, 19, 29]. Figure 1 summarizes the gross left-right asymmetries in the Ciona larval CNS. These include the larval visual organ, the ocellus, which is located on the right side of the brain vesicle, and the otolith-associated antenna cells on the left side, which, along with the otolith pigment cell comprise the gravity-sensitive otolith organ. Also asymmetrically located in the ventral portion of the left brain vesicle are the 15 coronet cells, which have been speculated to be components of a sensory system, but of unknown function. The coronet cells are dopaminergic [30] and receive their name from the coronet cells of the saccus vasculosus, an organ that serves as a photoperiodic and seasonal sensor in teleosts [31]. Many other examples of left-right asymmetry are evident from the
Ciona synaptic connectome, including the left-right asymmetric projection of axons [7].

We show here that the disruptions to left-right asymmetry caused by dechorionation extend beyond the sensory systems and are observed throughout the length of the larval CNS. Moreover, the disruptions vary extensively from larva to larva. Disruptions are observed not only to the cellular anatomy of larvae, but to the connectivity of neurons and to larval behavior, as well. While the anatomy and behavior of early-dechorionated larvae on average was highly abnormal, we find that among dechorionated larvae a subpopulation with apparently more normal CNS development and behavior can be identified, as well as a subpopulation of larvae with mirror-image CNS asymmetry and behavior.

\section{Results}

Profound and highly variable defects to the pigmented sensory systems caused by early dechorionation Early dechorionation of tunicates is known to give developmental defects, including to the CNS [26]. 
However, the extent and range of developmental abnormalities resulting from early dechorionation has not been fully characterized. The pigmented cells of the brain vesicle ocellus and the otolith sensory organs are perhaps the most easily assayed asymmetries in the Ciona body, imaged here with a compound microscope, but visible even under a simple dissecting scope (Fig. 2). The pigment cells are critical for the proper functioning of these sensory organs [32, 33]. The otolith contains a single large melanized pigmented cell attached to the ventral surface of the brain vesicle. The melanin appears to contribute to the function of the pigment cell by increasing its specific gravity by chelating ions such as potassium, calcium, and zinc [34]. When a larva changes its orientation with respect to gravity, the movement of the pigment cell within the ventricle is sensed by the antenna cells. The pigmented cell of the ocellus directionally shades the Group I photoreceptor outer segments and allows a larva to determine the direction of light by performing casting swims [9]. In the non-dechorionated Ciona larva, the otolith pigment cell appears nearly spherical and is found near the midline (Fig. 2a). By contrast, the pigment cell of the ocellus forms a shallow cup and is found on the right side of the brain vesicle, slightly posterior to the otolith.

To determine what effect dechorionation had on the otolith and ocellus pigment cells, we dechorionated embryos either early or late (one cell and late tailbud stages, respectively) and then assessed $25 \mathrm{hpf}$ larvae for pigment cell morphology. Control larvae whose chorions were not removed showed the expected phenotype for pigmented cells (Fig. 2a) (38 normal of 40 total; of the two larvae remaining, one showed otolith and ocellus pigment cells at the midline, while another showed split/double otolith pigment clusters with an otherwise normally positioned ocellus). Late-dechorionated larvae showed the expected pigmented cell phenotype and asymmetry in all cases ( 28 normal/28 total), indicating that dechorionation after the stage at which asymmetries are established appears to preserve normal asymmetry, consistent with previous reports on the timing of asymmetry establishment in ascidians [20, 28]. By contrast, when embryos were dechorionated early, a range of abnormalities were observed in the resulting larvae with respect to the non-dechorionated and late-dechorionated larvae. Of 44 early-dechorionated larvae examined, only 8 had cells that would be classified as an otolith and an ocellus pigment cell based on their morphology and that showed proper left-right asymmetry; an equal number showed mirror-image reversals of the pigment cells. In eighteen larvae, we observed both pigmented cells positioned at the midline (e.g., Fig. 2c, i). In the remaining nine larvae, the pigmented cells either lacked the characteristic spherical or cup-shaped

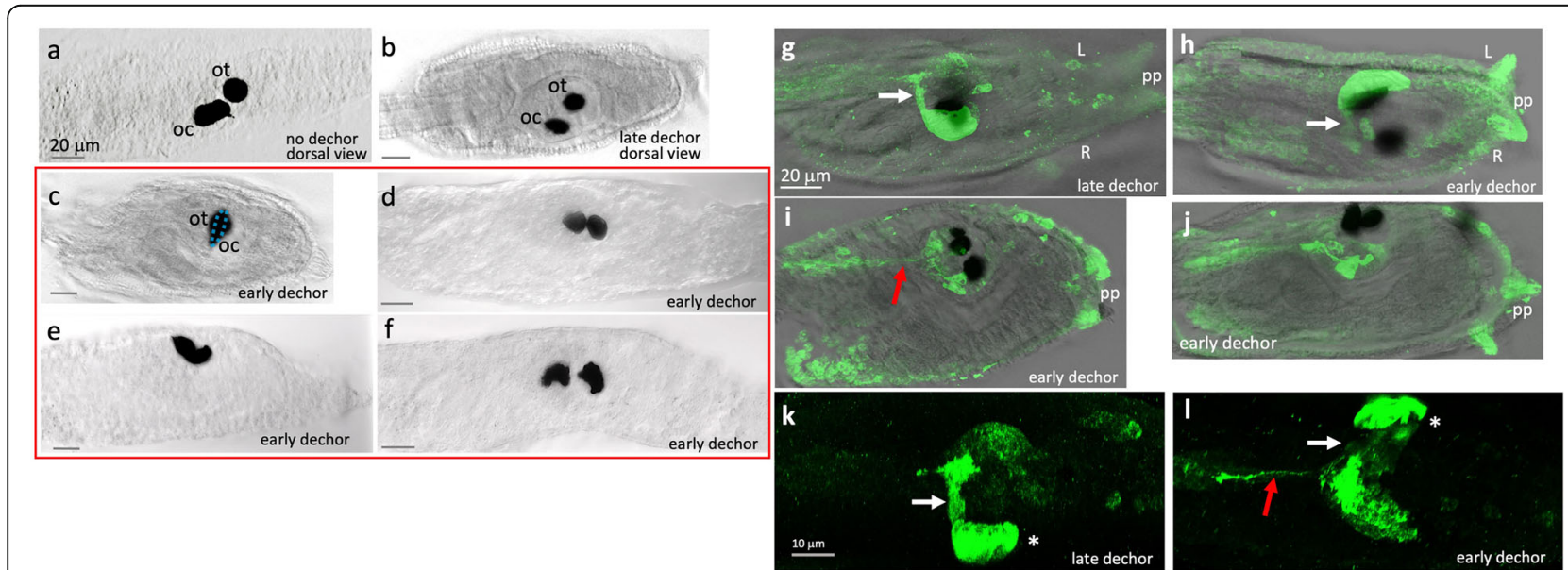

Fig. 2. Disruptions to the ocellus caused by early and late dechorionation. $\mathbf{a}, \mathbf{b}$ Pigment cells in representative non-dechorionated and latedechorionated larvae, respectively. c-f Representative larvae showing a range of pigment cell defects in early-dechorionated larvae, including overlapping otolith and ocellus at the midline (ocellus is outlined in blue) (c); two pigmented structures both resembling otoliths (d, see also i); a single large pigment spot_-possibly two cells (e); and two pigmented structures, both resembling ocelli (f). $\mathbf{g}-\mathbf{I}$ Photoreceptors in early- and latedechorionated larvae immunostained with anti-Arrestin. $\mathbf{g}$ Late-dechorionated larva. $\mathbf{h}$ Early-dechorionated larva showing left-right reversal of photoreceptors. $\mathbf{i}$, $\mathbf{j}$ Examples of early-dechorionated larvae with abnormal numbers and locations of photoreceptors. $\mathbf{k}$, I Late- and earlydechorionated larvae, respectively, showing apparently normal photoreceptor development in the late-dechorionated larva, while in the earlydechorionated larva the photoreceptor cluster is reversed, and while most projections are targeted correctly, one or more is projecting posteriorly. White arrows indicate properly targeted photoreceptor projections, and red arrows indicate aberrant photoreceptor projections. Asterisk indicates the location of the Group II photoreceptors. Abbreviations: ot, otolight; oc, ocellus; pp, palp; dechor, dechorionation; L, left; R, right 
morphologies or displayed an unexpected combination of morphologies, suggesting that in some cases two otolith or ocellus pigment cells had formed (see Fig. 2c- $\mathrm{f}$ for a range of pigment cell morphologies). We also observed a single larva which lacked pigmentation entirely.

\section{Disruption of photoreceptors by early dechorionation}

Immunostaining with an anti-Arrestin antibody labels the Group I and II photoreceptor cell bodies and their axons [35]. The axons are observed as a bundle projecting to the posterior brain vesicle (Fig. 2g, white arrow), where they synapse to relay interneurons [7]. This pattern of Arrestin labeling was observed in all latedechorionated larvae examined ( $\mathrm{n}=12$; Fig. $2 \mathrm{~g}, \mathrm{k}$ ). By contrast, nearly all early-dechorionated larvae had highly abnormal Arrestin staining patterns (19 of 23), while few showed the typical Arrestin distribution (4 of 23). Those showing abnormal patterns $(\mathrm{n}=19)$ included apparent left-right reversals (9 of 19) (Fig. 2h, l), no recognizable photoreceptors at all (5 of 19), or irregular or loosely structured photoreceptor clusters including many which no longer showed the characteristic close apposition to the ocellus pigment cell (Fig. $2 g-j$ ). For example, the larva shown in Fig. 2i has two well-separated clusters of photoreceptors, each associated with a pigment cell. Moreover, the projections from these photoreceptors project much more posteriorly than that they do in control larvae (red arrow), indicating that the photoreceptor connectivity in the early-dechorionated larvae may be highly irregular. Figure $2 \mathrm{l}$ shows an enlargement of a larva with a left-right mirror inversion, but while most of the photoreceptors project correctly (white asterisk), some photoreceptors appear to have missed their $\mathrm{pBV}$ targets and instead project too posteriorly (red arrow). We also observed consistent staining of palps ( $p p$ in Fig. 2) with the Arrestin antibody in early-dechorionated larvae, but not in late-dechorionated larvae or nondechorionated larvae [35]; the reason for this is not clear.

\section{Antenna cells and coronet cells}

We also assayed for the presence of the paired antenna cells and the coronet cells, as these sensory organs display a stereotyped asymmetry in the larval body (Fig. 1). We used an in situ strategy to label these organs. By using the hybridization chain reaction (HCR) in situ procedure (Molecular Instruments), two fluorescent probes were imaged simultaneously in the same larva, allowing us to assess correlations in symmetry defects between organs. The glutamatergic antenna cells project from the otolith to relay neurons in the posterior brain vesicle and can be visualized with probes to the vesicular glutamate transporter transcript (VGLUT)
$[10,36]$. While VGLUT also labels photoreceptors, palp neurons, and epidermal sensory neurons (ESN), the antenna cells can be readily identified by their shape and position in the brain vesicle and easily distinguished from photoreceptors. We assessed antenna cells after both early and late dechorionation (Fig. 3). In latedechorionated larvae, the VGLUT label allowed us to identify the antenna cell pair in most larvae (10/11); the antenna cells in these larvae showed the expected asymmetry (Fig. 3a). In these larvae, the photoreceptors were also identifiable in all larvae and were found in the expected position on the right side of the BV. In early-dechorionated larvae, by contrast, antenna cells were recognized in $58 \%$ of the larvae observed (11/19), and when present, many showed sidedness defects, positioned on the right instead of the left side ( 8 of 11) (Fig. 3b, d). In those cases where VGLUT labeling indicated the presence of antenna cells, the cells were always observed as a pair, as would be expected, never as single cells or never more than two. The photoreceptors were absent at nearly the same rate as the antenna cells $(9 / 19)$, but the presence or absence of the one did not necessarily indicate the presence or absence of the other (data not shown).

The coronet cells of Ciona are likely dopaminergic as they label with an in situ riboprobe for tyrosine hydroxylase $(T H)$ as well as by anti-dopamine immunolabeling [37]. A patch of $T H$-positive cells of the expected size and position (posterior to the antenna cells, and at the left ventral side of the anterior BV) was observed in all late-dechorionated larvae (11/11), as has been described previously [37] (Fig. 3a). Most early-dechorionated larvae (17/19) also had a $T H$ positive patch in the anterior brain vesicle, indicating the presence of coronet cells. Although the presence of coronet cells seemed robust compared to the antenna cells (and photoreceptor cells), sidedness appeared nearly random, with 7 located to the left of the midline and 10 appearing to the right.

While correlations between the presence/absence of antenna cells, coronet cells, and ocellus-associated photoreceptor cells were not apparent in earlydechorionated larvae, sidedness relations did show consistency. The coronet and antenna cells (when both present) were found on the same side. The photoreceptor neuron clusters were found opposite the antenna and coronet cells. That said, in earlydechorionated larvae, VGLUT labeling did not always reveal a coherent group of photoreceptor neurons, as would be seen in typical non-dechorionated larvae. This observation for VGLUT is consistent with the results for the Arrestin antibody (Fig. 2) which showed patchy or small clusters of labeling in some early-dechorionated larvae. 

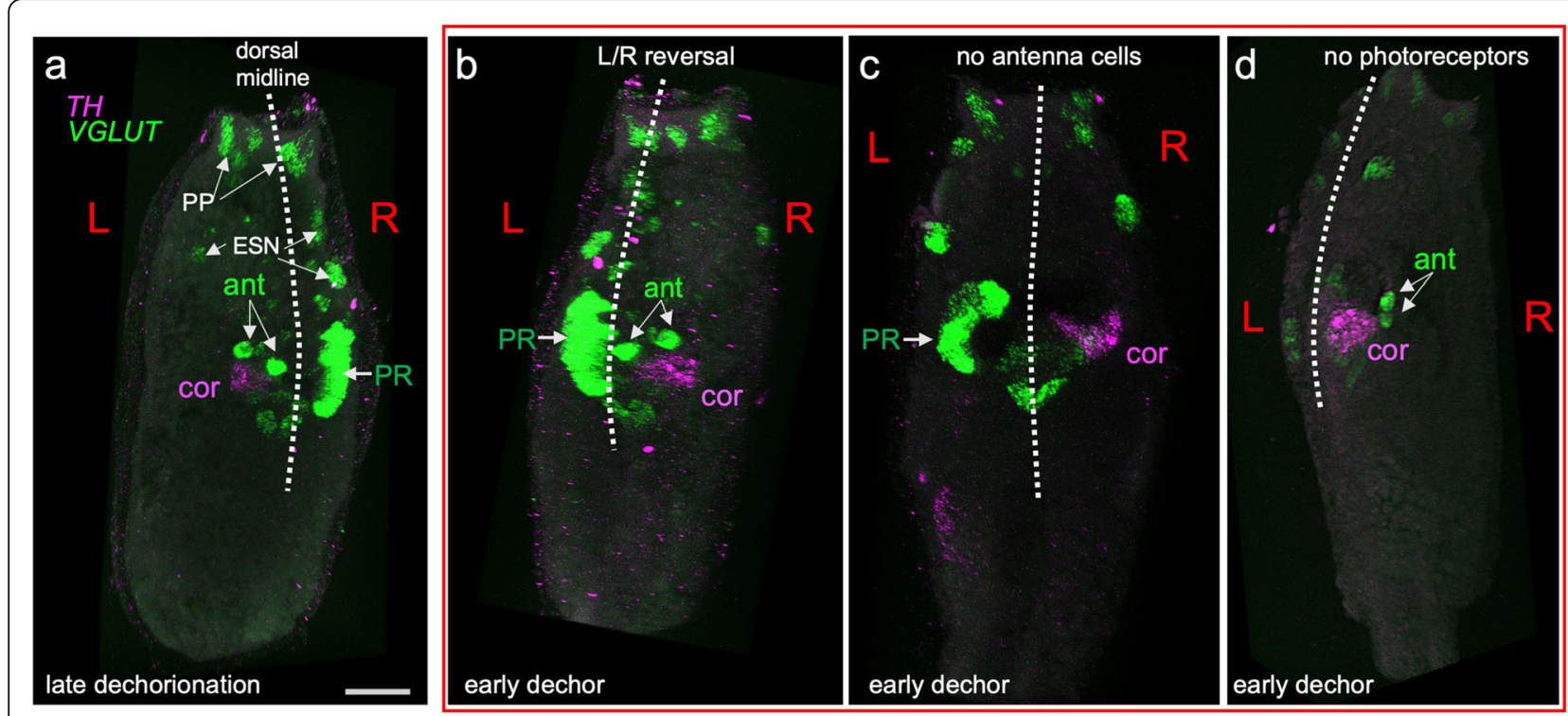

Fig. 3. Disruptions in sensory systems caused by early dechorionation. a A late-dechorionated larva showing the paired VGLUT-expressing antenna cells. Also labeled by in situ hybridization are the VGLUT-expressing photoreceptors and epidermal sensory neurons, and the tyrosine hydroxylase (TH)-expressing coronet cells. b-d Larvae represent a range of disruptions to sensory systems caused by early dechorionation. Abbreviations: pp, palps; ESN, epidermal sensory neurons; PR, photoreceptors; ant, antenna cell; cor, coronet cell. Dashed lines indicate midline. Scale bar in a is $10 \mu \mathrm{m}$

\section{Left-right asymmetry in the pBV}

The photoreceptors, antenna cells, coronet cells, and a subset of the ESNs all project to the pBV [7], where they synapse to several classes of interneurons, including the relay neurons, which in turn project posteriorly to the motor ganglion. In situ hybridization studies have shown that the pBV is made up of two distinct and nested domains, an anterior region of cholinergic neurons ( $V A C H$ $T$ expressing) and a posterior region of GABAergic neurons (VGAT expressing) (Fig. 4a [10];). When viewed laterally, where left-right asymmetry would not be evident, the overall complement and nested anterior-posterior domains of cholinergic and GABAergic neurons appear to be preserved in early-dechorionated larvae (Fig. 4b). However, as is evident in the early-dechorionated larva shown in Fig. 4b, the angle of the cholinergic and GABAergic neuron clusters with respect to the body axis often differed from the late-dechorionated larvae, suggesting a left-right asymmetry in the pBV.

The pBV left-right asymmetry is evident when the VGAT domain is viewed dorsally from the caudal end of the larva (Fig. 4c). When viewed from this perspective, the pBV VGAT neurons in late-dechorionated larvae cluster to form a right-facing crescent $(\mathrm{n}=12)$ (Fig. $4 \mathrm{~d}-\mathrm{f})$. In earlydechorionated larvae, the distribution of VGAT neurons in the pBV no longer shows this pattern (Fig. 4 g-i). Most (4/ 5) could be interpreted as having a reversed orientation for the VGAT, with the crescent open toward the left. Thus, like the sensory structures in the $\mathrm{aBV}$, the arrangement of interneurons of the pBV has an inherent left-right pattern, and this pattern is disrupted by early dechorionation.

\section{Asymmetric Pitx in the motor ganglion}

Unlike in the brain vesicle, the distribution of neurons in the motor ganglion shows bilateral symmetry. This is observed, for example, in the two cholinergic descending decussating neurons (ddNs) in the anterior MG, which are found paired across the midline, one right and one left. Posterior to the ddNs are right and left pairs totalling six cholinergic MGINs and ten cholinergic MNs [7, $10,38]$. While some variation has been observed between larvae in the number of glycinergic ascending contralateral inhibitory neurons (ACINs) and MNs, as well as how closely left-right neuron pairs are juxtaposed across the midline in the posterior MG, these asymmetries are rare and appear to occur at random in untreated larvae and thus are likely not driven by the Nodal leftright asymmetry pathway $[7,10]$.

Pitx gene expression, as a downstream target in the Nodal signaling pathway, is diagnostic for left-right asymmetry. In ascidian neurula embryos (Ciona and Halocynthia roretzi), it is expressed in the left epidermis and includes the prospective oral siphon primordium by tailbud stages [19, 39, 40]. In late-dechorionated Ciona larvae, we observed Pitx expression in the left motor ganglion, as well as faintly in the photoreceptors, and in the oral siphon primordium-a symmetric midline structure (Fig. 5a). Expression in the motor ganglion was restricted 


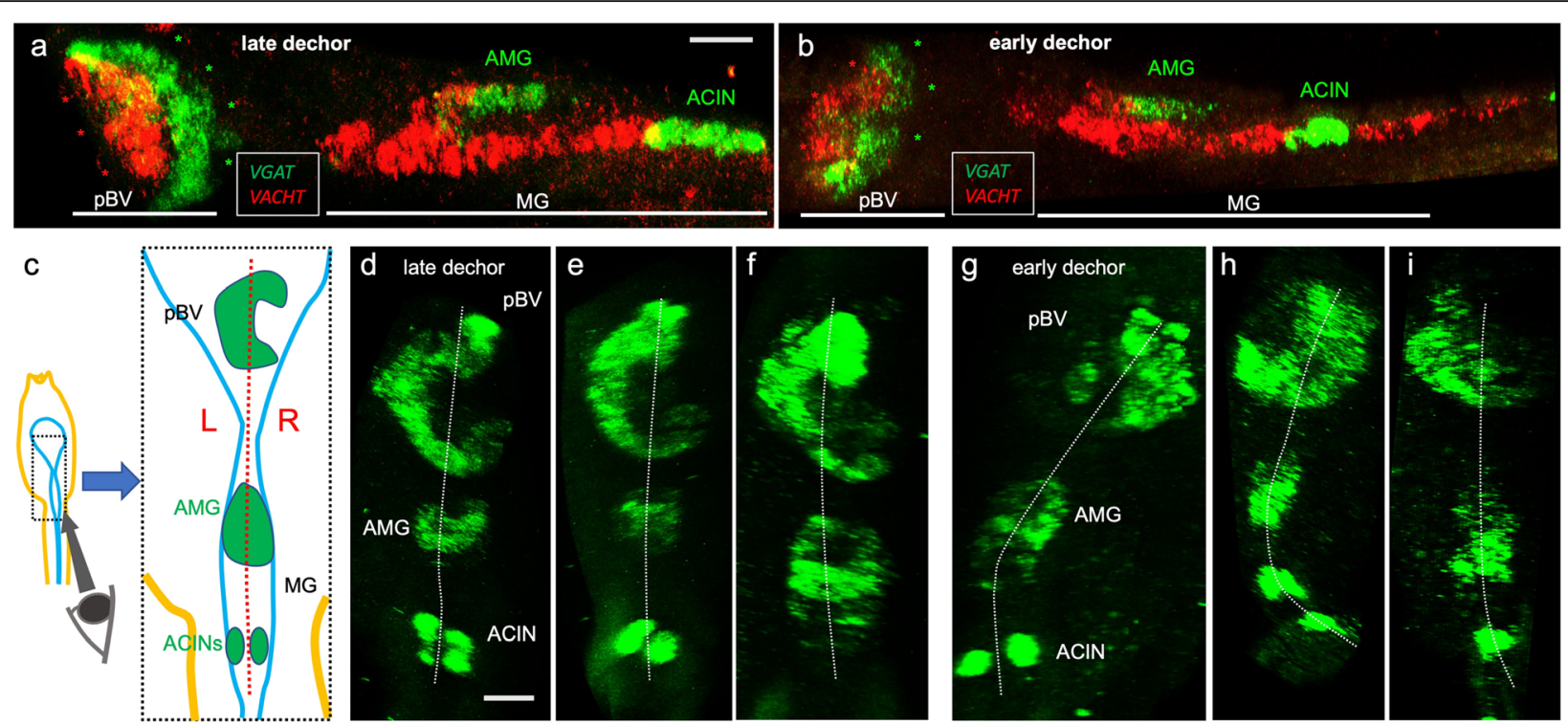

Fig. 4. a, b Double-labeled in situ hybridization for VGAT and VACHT shows similar patterns for both early- and late-dechorionated larvae in the layered domains of the pBV (left-lateral view; anterior is left). Also labeled are the VGAT-positive AMG neurons, just dorsal to the VACHT-positive (red) neurons of the MG, and anteriormost set of paired ACINs. c Diagram shows perspective for VGAT in situs shown in panels $\mathbf{d}-\mathbf{i}$. $\mathbf{d}$ - $\mathbf{f}$ Latedechorionated larvae show characteristic right-facing crescent of VGAT expressing cells in the pBV. $\mathbf{g}$-i The asymmetry of the pBV, as seen by VGAT expression, is disrupted in early-dechorionated larvae. Abbreviations: pBV, posterior brain vesicle; MG, motor ganglion; AMG, ascending motor ganglion neurons; ACIN, ascending contralateral inhibitory neuron

to its anterior portion and did not appear to extend to the $V G A T$-positive (glycinergic) ACIN cells (Fig. 5a). The leftright demarcation, however, is very clear, with little or no detectable Pitx expression in the right MG. This expression suggests that later Pitx expression, like that of neurula and tailbud stages, plays a role in left-right patterning. Moreover, just as early dechorionation disrupts embryonic Pitx expression, often resulting in bilateral epidermal expression, early dechorionation likewise disrupted the asymmetric expression of Pitx in the MG at the larval stage (Fig. 5b). Most early-dechorionated larvae showed bilateral expression of Pitx in the MG (4/6 bilateral; 1/6 no expression; $1 / 6$ left-sided); all late-dechorionated controls showed the left-sided pattern (8/8).

A previous study using a transgenic Pitx-promoter expression construct and in situ probes for Pitx isoforms also reported asymmetric expression in the left motor ganglion at late tailbud and hatching stages [41]. However, these labeling methods required early dechorionation, so it was not clear whether the asymmetric MG expression was typical. Our in situ patterns confirm these previous results, showing that left-right asymmetries are present in the MG at larval stages, despite the anatomical left-right symmetry in the number and distribution of MG neurons. Additionally, we can add to asymmetric larval Pitx expression a likely dependence on earlier Nodal-dependent events, since early dechorionation disrupts the leftdominant pattern of Pitx in the MG.
Left-sided AMPA receptor expression in the motor ganglion interneurons

While the MG approximates bilateral symmetry in its complement of cells, we found that like Pitx, a receptor for the neurotransmitter glutamate, the AMPA receptor $(A M P A R)$, is asymmetrically expressed in larval MG. In late-dechorionated Ciona larvae, in situ hybridization reveals strong $A M P A R$ expression in cells on the left side of the MG (Fig. 6a); expression is also evident anteriorly in the brain vesicle, as reported previously [10]. Cells on the right side of the MG show only faint $A M P A R$ expression. This pattern was observed in 10/10 of latedechorionated larvae examined. Like Pitx-labeled larvae of the same stage, larvae which had been dechorionated early did not show the dominant left-sided expression pattern for $A M P A R$, consistent with other asymmetries observed in the Ciona larval CNS. Some larvae showed reversals, with right-sided expression predominant (4/8; Fig. 6b), while others showed bilateral expression (3/8; Fig. 6c) and one was observed with the left-dominant pattern.

Two of the primary cell classes in the MG are the MNs and the MGINs, which can be distinguished by their expression of $M n x$ and $V s x$, respectively [42, 43]. We performed a triple in situ with $V s x, M n x$, and $A M P A$ $R$ to determine which cell classes expressed $A M P A R$ in the MG (Fig. 6d-h). AMPAR shows coexpression with $V s x$, but not $M n x(\mathrm{n}=5)$, indicating it is expressed in the MGINs and that these cells potentially have an 


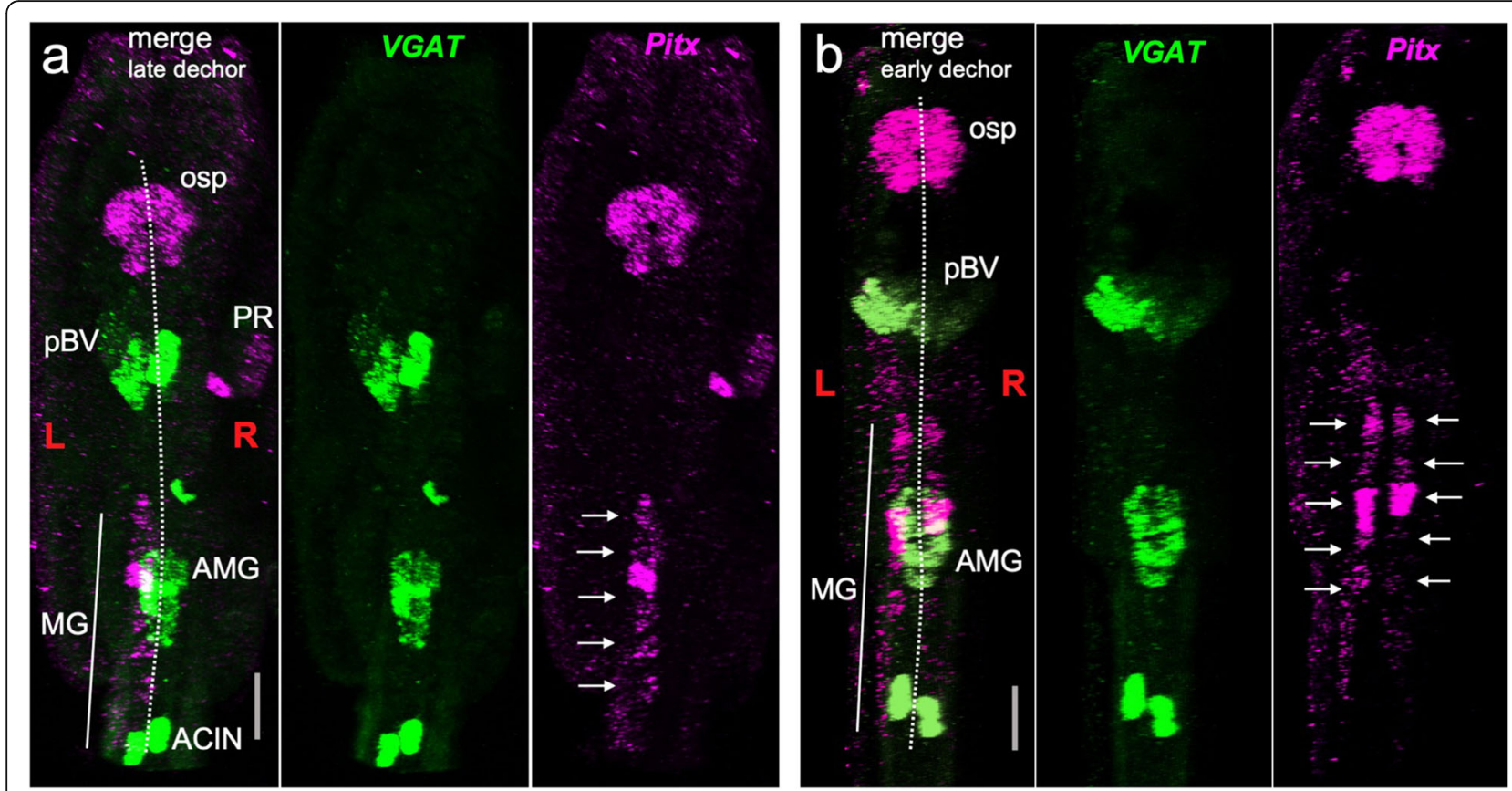

Fig. 5. The Pitx gene is expressed asymmetrically in larval Ciona robusta. a Detail of a late-dechorionated 25 hpf Ciona larvae showing Pitx expression by in situ hybridization co-labeled with VGAT (anterior is up; midline indicated by dotted line). Pitx shows left-sided expression in the MG (arrows), in contrast to VGAT which is expressed in the MG on both sides of the midline. Pitx expression in the osp is also bilateral. In this view, Pitx is also seen in the photoreceptor cells on the right side. $\mathbf{b}$ An early-dechorionated larva shows the same bilaterality for VGAT in the MG, and for Pitx in the osp, but Pitx in the MG is found on both left and right sides of the dorsal midline (arrows). Scale bars are $20 \mu \mathrm{m}$. Abbreviations: osp, oral siphon primordium; pBV, posterior brain vesicle; PR, photoreceptor; MG, motor ganglion; AMG, ascending motor ganglion neurons; ACIN, ascending contralateral inhibitory neuron

asymmetric, left-sided bias in their ability to respond to the neurotransmitter glutamate, suggesting a possible mechanism for asymmetric (i.e., curved) swim trajectories. Our Mnx expression appears expanded posteriorly compared to the pattern previously described using an $M n x$ reporter [43]; our labeling may show the third $\mathrm{MN}$-absent in previous samples-perhaps due to stage differences. As for $V s x$ expression, we speculate that our labeling shows the MGINs as well as additional neurons in the MG, possibly the anterior pair of ACINs and the posterior motor ganglion neurons (PMGNs) [7].

\section{Disruptions to larval behavior by dechorionation}

A strength of the Ciona system, which combines a very small and well-documented nervous system with quantifiable behaviors, is the potential for identifying the roles of individual neurons in underlying behavioral control. Unfortunately, many of the techniques that could aid in this analysis, such as transient transgenesis and CRISPR, require early dechorionation. As detailed above, early dechorionation results in profound and variable defects throughout the larval CNS. Consistent with the defects in CNS, we find that the behavior of early-dechorionated larvae, and to a much lesser extent late-dechorionated larvae, is abnormal when compared to non-dechorionated controls.

To assess the behavior of larvae, we used a previously described gravitaxis assay [8]. In this assay, the behavior of larvae is recorded in a vertically mounted and covered 6$\mathrm{cm}$ petri dish. In response to a dimming of ambient light, the larvae initiate robust negative gravitaxis swims (i.e., upward swimming). Under constant illumination, the larvae show no up or down bias in their swims. Thus, this assay demonstrates the integration of gravity and visual inputs and gives a measure of the functioning of both the visual and gravitaxis systems. For these assays presented here, which consisted of dimming a 505-nm light from 600 to 0 lux (while recording with constant 700-nm illumination), we recorded both the percentage of larvae responding to the dim, which was evident in recordings as swimming behavior initiated immediately following the light dim, as well as the direction of swim trajectories with respect to gravity for those larvae that did respond. All behavior assays were analyzed as described [8] and see the "Methods" section]. Briefly, trajectories were determined by assessing the starting and ending positions in the $20 \mathrm{~s}$ following dimming. They were then assigned to the $90^{\circ}$ wedges, as shown in Fig. 7a, b. The values presented below are the averages and variations $( \pm$ S.D.) between clutches 

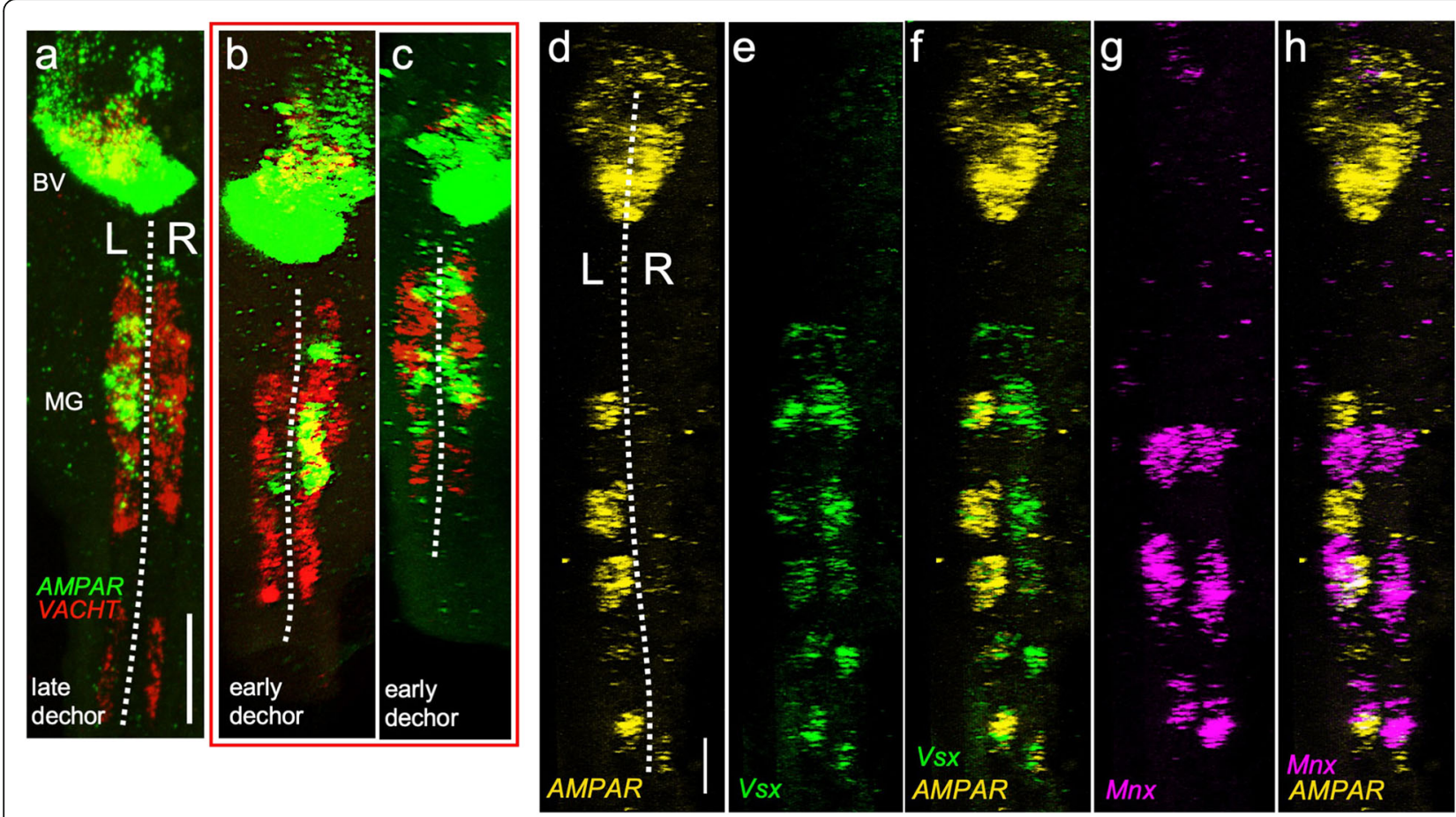

Fig. 6. Asymmetric AMPA receptor expression in the motor ganglion. a AMPA receptor (AMPAR) is expressed in the left motor ganglion of latedechorionated larvae. Also shown are VACHT-expressing cells, which are found on both left and right sides of the MG. b, c Asymmetric AMPAR expression is disrupted by early dechorionation. Phenotypes include reversals $(\mathbf{b})$ and bilateral expression (c). Panels $\mathbf{d}-\mathbf{h}$ show the same larva, triple labeled for AMPAR, Vsx, and Mnx. Asymmetric AMPAR is coexpressed with Vsx, but not Mnx, a marker of motor neurons. Dashed lines indicate midline. Scale bar in a is $20 \mu \mathrm{m}$ and $10 \mu \mathrm{m}$ in $\mathbf{d}$

of larvae for each condition. The number (n) represents the total number of larvae analyzed.

While $100 \%$ of the non-dechorionated control larvae responded to the $\operatorname{dim}(n=55)$, we observed that $83 \pm$ $29 \%(n=42)$ of early-dechorionated larvae responded. However, unlike the controls, which displayed a strong bias toward upwards swimming (96.1 $\pm 3.5 \%$ UP; $n=$ 55 ), only $36.2 \pm 6.6 \%$ of the early-dechorionated larvae $(n=27)$ that responded to the dim swam upwards, while $45.4 \pm 7 \%$ swam downwards and $18.4 \pm 11 \%$ swam sideways, illustrating a clear difference between control and early-dechorionated larval behavior (Fig. 7a, $p<0.00001$ ). Figure 7c (and Additional file 1: Movie S1) shows representative swims for control and dechorionated embryos. The swims are indicated by temporal projections of the swims over $20 \mathrm{~s}$, which appear as lines. By comparison to early-dechorionated larvae, the behavior of late-dechorionated larvae was more similar to controls. While $97.4 \pm 3.6 \%$ of our nondechorionated control larvae $(\mathrm{n}=140)$ for this assay responded to the dim, $94.4 \pm 7.9 \%$ of latedechorionated larvae $(n=61)$ responded as well. We observed a bias toward upwards swimming in both controls (94.9 $\pm 0.5 \%$ UP; $n=136)$ and late-dechorionated larvae (77.9 $\pm 8.6 \%$ UP; $n=57$ ) (Fig. 7b, c, $p>0.05$ ).
In addition, the swimming characteristics of dechorionated larvae were qualitatively different from nondechorionated control larval swimming (Fig. 7d). We observed that the average swimming speed of earlydechorionated larvae $(n=13)$ was $0.84 \pm 0.45 \mathrm{~mm} / \mathrm{s}$, while the average speed of their controls $(n=15)$ was $2.06 \pm 1.18 \mathrm{~mm} / \mathrm{s}(p=0.0001)$. The differences in swim speeds can be observed in Additional file 1: Movie S1. Late-dechorionated larvae also tended to swim at slower average speeds than their non-dechorionated controls. The average swimming speed of late-dechorionated larvae $(n=11)$ was observed to be $0.87 \pm 0.21 \mathrm{~mm} / \mathrm{s}$, while their controls $(n=60)$ swam $2.17 \pm 0.59 \mathrm{~mm} / \mathrm{s}$ on average $(p<0.00001)$. Furthermore, the average maximum speed at which late-dechorionated larvae were able to swim $(4.12 \pm 2.47 \mathrm{~mm} / \mathrm{s})$ was significantly different from the average maximum speed of their non-dechorionated controls $(7.06 \pm 1.58 \mathrm{~mm} / \mathrm{s} ; p=0.0003)$. This difference in swimming speed is likely not attributable to a different pattern generation for swimming, as no difference was observed between the number of tail beats per second in late-dechorionated larvae $(2.35 \pm 0.75$ flicks $/ \mathrm{s} ; n$ $=12)$ compared to their controls $(2.00 \pm 0.53$ flicks $/ \mathrm{s} ; n$ $=30 ; p>0.05)$. This suggests that the difference in speed might be mechanical, perhaps due to the reduced 

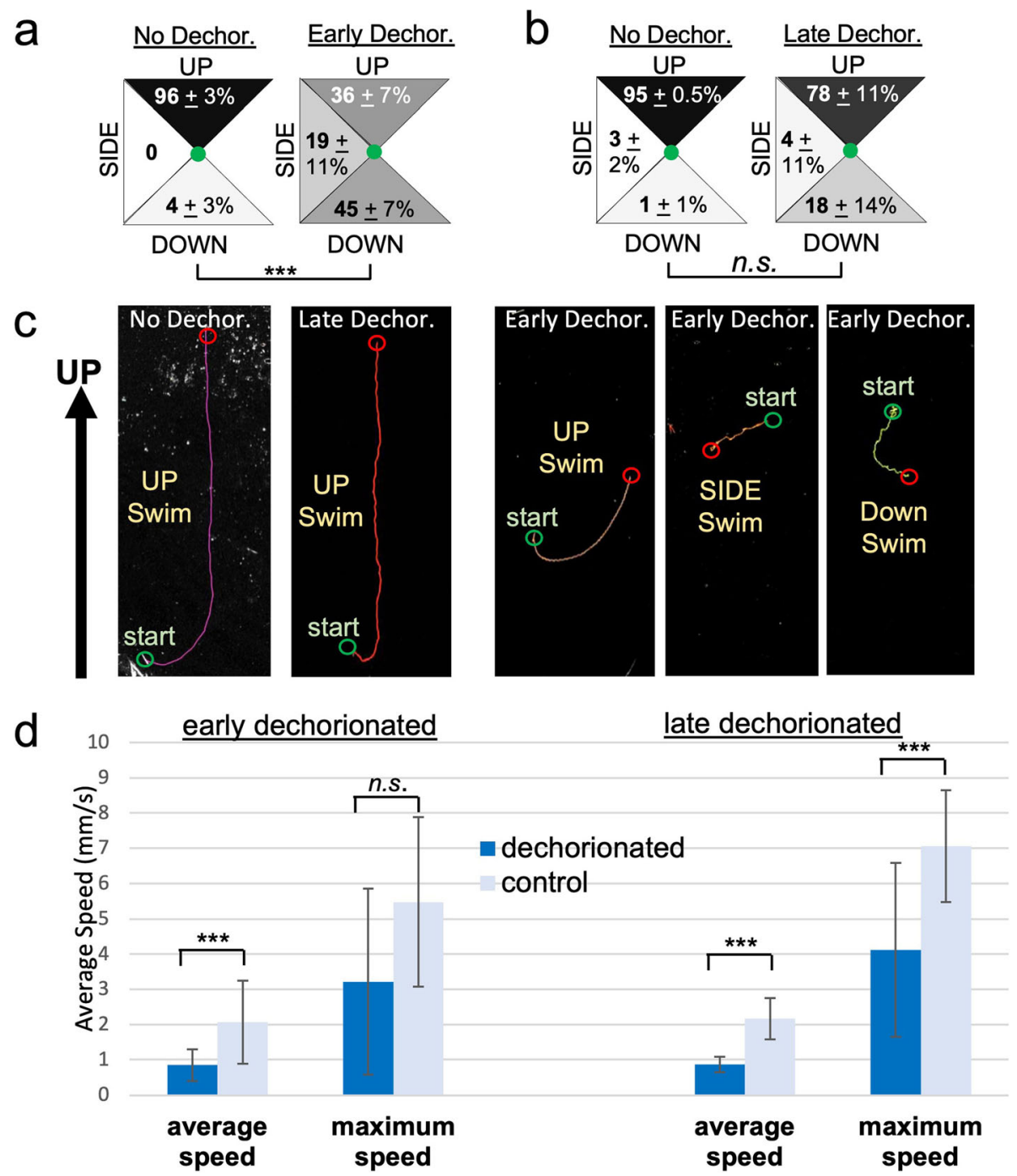

Fig. 7. Behavioral disruptions caused by dechorionation. a Early-dechorionated larvae have disrupted negative gravitaxis (upward swimming). (Percentages are derived from three separate clutches and two movies per clutch; see text for details.) b The negative gravitaxis behavior of latedechorionated larvae more closely resembles non-dechorionated controls than do early-dechorionated larvae. (Percentages are derived from two separate clutches and two movies per clutch.) c Representative dimming-induced swims in non-dechorionated, late-dechorionated, and earlydechorionated larvae. Lines represent swim trajectories projected across 20 s. d Both early- and late-dechorionated larvae swim more slowly than do non-dechorionated controls

amount of test in dechorionated larvae, making the larvae less rigid, particularly the larval median fin, which spans the rostral-to-caudal extent of the dorsal and ventral midlines. Supporting this idea, previous work shows that in animals that have not been dechorionated, dynamic interactions between test and tunic continue modeling the larval surface well after hatching [44]. Additionally, other research has shown that while fin formation still occurs in dechorionated Ciona, the resulting fins were reduced in size, although these dechorionations were performed early, just after fertilization [45]. We also did not observe any significant differences between the swimming path tortuosity of early- or late-dechorionated larvae and their respective control non-dechorionated larvae (data not shown).

\section{Selection of early-dechorionated larvae for normal and} mirror-image behaviors

In many larvae, disruptions to left-right asymmetry pathways give rise to a range of defects, from mixed or ambiguous asymmetry, to mirror-image reversals, and finally to a subset of larvae with apparent normal leftright asymmetry [46]. In early-dechorionated Ciona, we observed variation in both the number and position of sensory cells (photoreceptors and antennae cells), as well as variation in the shape of cell clusters in the pBV, and 
in gene expression (Pitx and AMPAR) in the MG. However, within all of the early-dechorionated clutches of larvae we assessed, there was usually a small fraction with either apparent normal development, or what appeared to be perfect mirror-image reversals. Likewise, we observed that a small fraction of the earlydechorionated larvae showed the expected upward swimming in response to dimming. Given these observations, we attempted to select early-dechorionated larvae based on their behavior, in order to determine if normal behavior correlated with more normal CNS development. Moreover, larvae selected this way might prove to be useful for assays or protocols requiring early dechorionation.

For the selection procedure, 23-24 hpf larvae were placed in $10-\mathrm{cm}$ agarose-coated petri dishes and observed under a stereomicroscope. The light was briefly dimmed and larvae that responded to the dimming with vigorous upward swimming were picked with a BSAcoated micropipette tip and transferred to a new petri dish (see details in the "Methods" section). From approximately 600 dechorionated larvae, we would recover 4-7 larvae with this method in about $15 \mathrm{~min}$. At $25 \mathrm{hpf}$, the behavior of the selected larvae was then reassessed and recorded in the gravitaxis assay, as described above. We observed that $77.2 \pm 12 \%$ of the selected earlydechorionated larvae $(n=23)$ swam up in response to dimming. By contrast, only $34.3 \pm 8.1 \%$ of unselected larvae $(n=12)$ swam upwards (Fig. 8a). Finally, $96.7 \pm$ $4.7 \%$ non-dechorionated control larvae $(n=35)$ swam upwards after dimming. Thus, we are able to select for larvae whose behavior more closely matches that of the non-dechorionated controls.

The left-right asymmetry of the selected larvae was examined by in situ hybridization, using the VGLUT and $A M P A R$ probes, as well as by examining the pigmented cells of the otolith and ocellus. For larvae that had been selected by the behavioral assay (from two separate clutches), 14 of 33 examined had correctly positioned pigment cells, while 16 had what appeared to be perfect reversals, two had the pigmented cells at the midline, and a single larva was observed with three pigment cells, likely two ocelli and a single otolith pigment cells. By contrast, in non-selected larvae, pigment cell reversals (10 of 20) were more prevalent than the normal pattern ( 4 of 20) or than midline placement of both otolith and ocellus pigments (6 of 20); a single animal in the latter category showed a split/double ocellus, positioned posteriorly to a single otolith. To further compare selected and non-selected larvae, we used VGLUT in situ hybridization to assess two easily identifiable features based on their position and morphology, the asymmetrically placed left-ventral antenna cell pair and rightsided photoreceptors. In non-selected larvae, only three of twenty-three larvae examined showed the expected left-side antenna cells together with right-sided photoreceptors (13\%); one showed a mirror-image reversal with left-sided photoreceptors and ventral-right antenna cells. Of the remaining nineteen larvae, seven had photoreceptors (whether right or left) without antenna cells (30\%), while eleven had identifiable antenna cells, but no photoreceptors (48\%). Of thirty-three selected larvae examined, thirty had both photoreceptors and antenna cells (91\%), that number evenly split between larvae with normal asymmetry (antenna cells on left, photoreceptors on right) and inverted, mirror-image asymmetry (i.e., reversal). The remaining three included a single larva with ectopic photoreceptors (this larva also had three pigment cells), one with no recognizable photoreceptors, and one with neither photoreceptors nor antenna cells (though other VGLUT-positive cells were present). In all cases, pigment asymmetry determined by bright-field imaging correlated with asymmetries as determined by gene expression. In other words, all of the above larvae which had been determined to have mirror-image pigment reversals also showed a corresponding reversal of gene expression, while those showing the typical pigment pattern also showed normal gene expression. A subset of larvae were also cohybridized with the $A M P A R$ probe, which showed that mirror-image reversals in selected larvae determined by VGLUT expression were accompanied by a reversal of AMPAR in the MG (4/4). Larvae with normal asymmetry, by contrast, showed left-sided $A M P A R$ in the MG (5/6), with a single exception showing bilateral $A M P A R$. These results provided further support that mirror-image reversals are consistent across the CNS.

Because the selected early-dechorionated larvae appeared to consist of an equal mixture of normal and mirror-image left-right reversals, we undertook to determine if the behaviors of these two phenotypes were qualitatively different. Ciona larvae show a highly reproducible asymmetric behavior. When viewed from above, rather than from the side as in the gravitaxis assay, the larvae can be seen responding to light dimming with curved or spiraling swims, and the majority of these (> $80 \%$ ) are counterclockwise [9]. For the assay here, the selected larvae, gathered from two clutches, were placed in two groups, normal or inverted, based on the leftright distribution of the pigment cells. We recorded the behavior of six normal and five inverted larvae. All larvae were recorded in three to five dimming assays with 5-min recovery intervals between each (see the "Methods" section), and in total, 19 swims from inverted larvae and 16 swims from normal larvae were recorded. For the larvae with normal left-right pigmentation, 14 of the16 swims were counterclockwise (87\%), one was clockwise, and one was unscorable. For the larvae with 

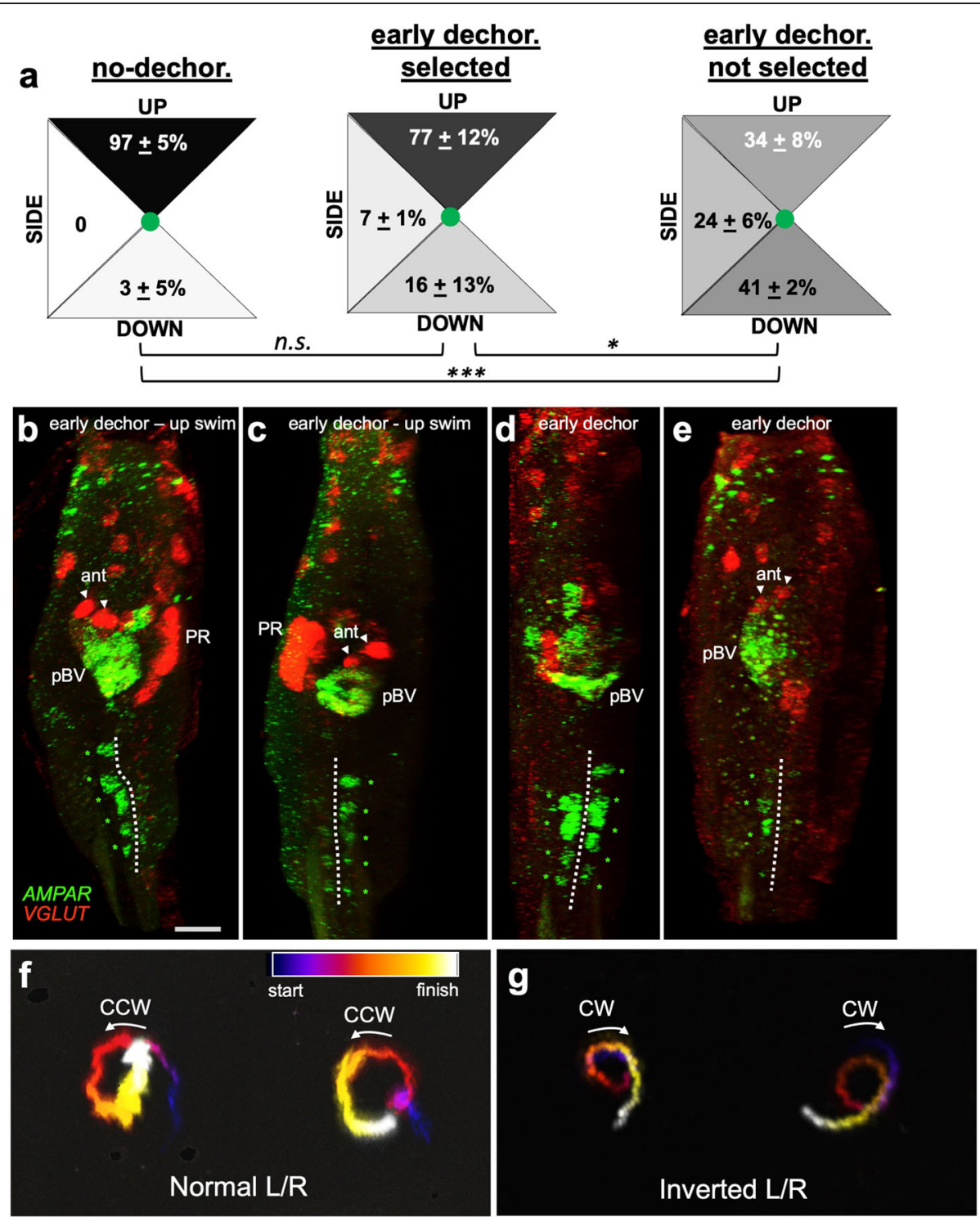

Fig. 8. a Gravitaxis of larvae pre-selected for their upward swimming behavior (selected) and their non-dechorionated, and non-selected siblings (not selected), whose combined numbers represent two separate fertilizations. b-e In situ hybridization for VGLUT and AMPAR of earlydechorionated larvae, either selected for their upward swimming behavior $(\mathbf{b}, \mathbf{c})$ or not selected $(\mathbf{d}, \mathbf{e})$. $\mathbf{f}, \mathbf{g}$ Temporal projection of swimming trajectories for selected larvae with normal (f) and mirror-image left-right asymmetry (g) following light dimming (projections over $13 \mathrm{~s}$ ). Abbreviations: ${ }^{*} p<0.05 ;{ }^{* *} p<0.001$; n.S., not significant; $\mathrm{pBV}$, posterior brain vesicle; ant., antenna cells; PR, photoreceptors; L/R, left-right. Dashed lines indicate midline. Scale bar in $\mathbf{b}$ is $10 \mu \mathrm{m}$

reversed left-right pigmentation, 15 of 19 swims were clockwise (79\%), one was counterclockwise, one was straight, and two were unscorable. Representative swims for the two groups are shown in Fig. 8f, g. The panels show temporal projections of swims in the $13 \mathrm{~s}$ following dimming. The projections are presented as heat maps to indicate the starts and finishes of the swims. Representative swims for the two groups are also presented in Additional file 2: Movie S2. These results show that larval asymmetry, whether normal or mirror-image reversed, correlates to asymmetric swim behavior, clockwise or counterclockwise, and therefore links this behavior to the patterning which establishes left-right asymmetry earlier in the developing neurula.

\section{Discussion}

The left-right asymmetry of the Ciona larval CNS has been well documented [7, 29]. The Ciona connectome further highlights the left-right asymmetry of the larval CNS [7], evident both in the localization of specific neuron classes, as well as in their synaptic connectivity. The previously undescribed left-right 
asymmetries described here for Ciona larval CNS anatomy, gene expression, synaptic projections, and behavior all are disrupted by early dechorionation, suggesting they are driven by the common mechanism, despite being highly variable. Although normal asymmetric Nodal signaling has been shown to be disrupted by dechorionation, the extent to which the defects described here can be attributed to disruption of Nodal signaling will require further investigation.

Given the profound disruptions to CNS anatomy caused by early dechorionation, it is hardly surprising that the behavior of dechorionated larvae is abnormal. What was more unexpected was that within a clutch of dechorionated larvae, individuals with apparently normal CNS anatomy and behavior could be found. Equally unexpected is that larvae with mirror-image reversals could be isolated and that the behavior of these larvae in a dimming assay also represented a mirror-image reversal with respect to normal larvae. Asymmetric behaviors have been described in a range of metazoans [47]. Among the chordates, the consequences of disruptions to CNS left-right asymmetry on behavior have been detailed most extensively in zebrafish [48]. Notably, zebrafish larvae show a similar response to Ciona larvae in response to dimming light-circular swimming. As a population, zebrafish larvae showed no bias for clockwise or counterclockwise swimming in response to dimming, yet individual larvae in repeated trials show a strong bias toward one direction [49]. This acquired asymmetry appears to be related to the Nodalindependent hand preference in humans. However, other asymmetric behaviors in zebrafish are dependent on the Nodal pathway [50].

While at the cellular level the MG appears to have left-right symmetry, the expression of Pitx and AMPAR is asymmetric. Although asymmetric Pitx expression in the motor ganglion has been reported previously [41], we report here that this asymmetric expression is disrupted by dechorionation. This is also true for the left-sided MG AMPAR expression reported here. The first signs of left-right asymmetry in ascidians are Pitx and nodal expression in the left epidermis [19, 20, 40]. The left epidermal expression in Ciona extends into the tailbud stages, and by late tailbud, nodal expression is observed in the left brain vesicle and endoderm [26]. It is possible this late tailbud expression could also include the MG precursor, as Pitx is expressed there [41]. The identity of neurons targeting the AMPAR-expressing MGINs in the MG is unclear. There appear to be no glutamatergic neurons that synapse directly to the MGINs. All VGLUT-positive neurons (i.e., glutamatergic) in the Ciona larva are sensory cells (photoreceptors, antenna cells, and epidermal sensory neurons) [10]. None of these synapses on the MGINs [7]. Instead, the MGINs receive extensive synaptic input from the GABAergic and cholinergic pBV relay neurons, which themselves receive direct input from the photoreceptor, antenna cell, and coronet sensory cells. However, there are glutamatergic neurons that do project to the MG. These are a subgroup of the ESNs known as the posterior apical trunk epidermal neurons (pATENs). The pATEN projections enter the MG dorsal to the MGINs where they synapse to AMG neurons (see Fig. 1 for relative positions of pATENs and AMG neurons to other neurons of the CNS). However, the pATENs also appear to make synaptic contact to the basal lamina dorsal to the MG near the AMGs [38]. It is possible that the release of glutamate to the basement membrane may be received by the MGINs, as the AMGs and the MGINs directly abut toward the anterior extent of the AMGs and are separated by one cell width toward their posterior. The asymmetric localization of the $A M P A R$ may be responsible for translating glutamate release into asymmetric muscle activation. In fact, stimulation of the ESNs causes counterclockwise circular swimming (Additional file 3: Movie S3), which would be predicted from preferential activation of the left flank of muscles. This may represent a pathway for evoking circular swims that is an alternative to, for example, the asymmetric projection of inhibitory antenna cell relay neurons to the MGINs $[7,8]$.

Despite the widespread use of methods such as transient transfection by electroporation that require early dechorionation in Ciona, and other ascidian species, results from such experiments should be interpreted cautiously, particularly given the highly variable nature of the asymmetry defects observed. Where appropriate, such as for in situ hybridization to tailbud or older embryos or larvae, the late dechorionation method described here provides a workable solution to this problem. In addition, the behavior-based selection procedure presented here is a solution when early dechorionation is unavoidable, although it is time-consuming and yields relatively few larvae. We found that the selected larvae appear to be reasonable approximations of normal larvae, as assessed by gene expression, pigmentation, and behavior, although half represent mirror-image reversals. We anticipate this procedure will be particularly useful for assessing behavior and CNS function, such as with genetically encoded calcium indicators, in transfected larvae.

\section{Conclusions}

We show that left-right asymmetric features of the Ciona larval CNS are profoundly disrupted following 
early removal of the chorionic membrane. These disruptions include the absence of particular neuron types, altered sidedness in CNS anatomy and gene expression, and likely differences in synaptic connectivity. These changes span the anterior-posterior extent defined by the sensory apparatus at the anterior $\mathrm{BV}$, through the relay neuron containing $\mathrm{pBV}$, to the MG. While later dechorionation (after the neurula stage) remedies many of these disruptions, we have devised an assay to find apparently normal-behaving larvae within clutches of early-dechorionated animals. Using this selection regime, we are able to isolate animals with expected symmetry (comparable to non-dechorionated animals) as well as animals which represent mirror-image reversals with respect to the left-right axis. Larvae with left-right reversals show corresponding behavioral reversals in a circular swimming assay compared to their non-mirrorimage siblings.

\section{Methods}

\section{Animal care}

Ciona robusta adults were collected from Santa Barbara Harbor and kept at the University of California, Santa Barbara, marine laboratory. Single clutches of larvae were obtained by collecting and mixing eggs and sperm from three adults, placing the zygotes at $18^{\circ} \mathrm{C}$ until they had reached the desired stage [18].

\section{Dechorionation}

Embryos were dechorionated using the sodium thioglycolate/protease method, as described previously [51]. For early dechorionation, eggs are incubated at room temperature in the dechorionation solution, beginning 2 min after fertilization. Eggs are washed in seawater $5 \times$ in $60 \mathrm{~mm} \mathrm{1 \%}$ agarose-coated plastic petri dishes, then moved to $18^{\circ} \mathrm{C}$ until the desired time post-fertilization is reached. For late dechorionation, the dechorionation solution is added to embryos at the late tailbud stage, about $14 \mathrm{~h}$ post-fertilization (hpf) [52]. Embryos are then washed in seawater, as above, and placed at $18^{\circ} \mathrm{C}$ in agarose-coated dishes. Following dechorionation, whether early or late, left-right sidedness of asymmetric features was always determined with reference to the dorsal midline.

\section{Immunohistochemistry and in situ hybridization}

Antibody labeling was carried out as follows: C. robusta larvae were fixed in seawater $+2 \%$ paraformaldehyde for $1 \mathrm{~h}$ at room temperature, before washing three times in PBS $+0.1 \%$ Triton X-100 (PBT). Larvae were placed in $\mathrm{PBT}+5 \%$ lamb serum for $1 \mathrm{~h}$ at room temperature and transferred to $\mathrm{PBT}+5 \%$ lamb serum with a $C$. robusta Arrestin antibody raised in rabbit (gift of Takehiro Kusakabe), at a dilution of 1:1000, overnight at $4^{\circ} \mathrm{C}$. Following five washes in PBT at room temperature, a secondary antibody, $\alpha$-rabbit AlexaFluor 488 (Invitrogen), was used at 1:1000 overnight at $4^{\circ} \mathrm{C}$, followed by five more PBT washes at room temperature before imaging.

In situ hybridization was carried out as previously described using the hybridization chain reaction (hcr) (v. 3.0 protocol of Molecular Instruments). Any given in situ hybridization included animals from multiple clutches, each clutch resulting from the mixture of sperm and eggs from at least three adults, as mentioned above. The mixing of animals from multiple clutches was followed for late- and for early-dechorionated animals, as well as for in situs on behavior-selected animals, in which case larvae from at least two clutches were included. For in situs, RNA probe sets were designed to the following Ciona genes: tyrosine hydroxylase (TH; NM_001032795.1), vesicular glutamate transporter (VGLUT; KH2012:KH.C3.324), vesicular GABA transporter (VGAT; NM_001032573.1), Pitx (KH2012: KH.L153.79.v1.A.SL2-1), the AMPA glutamate receptor (AMPAR; XM_018817034.1), and vesicular acetylcholine transporter (VACHT; NM_001032789.1). Each of these probe sets is found to hybridize identically in Ciona robusta (previously known as C. intestinalis, type A; the subject of the current study) and in the closely related $C$. intestinalis (previously known as C. intestinalis, type B). Larvae were imaged on Olympus Fluoview1000 or Leica SP8 confocal microscopes and images depicted for figures represent maximum intensity projections. Postacquisition analysis and rendering used Imaris v.9 or ImarisViewer v.9.5.1 software.

\section{Behavioral assays}

Dechorionated larvae were raised in $0.2 \%$ methyl cellulose in filtered seawater to prevent them from sticking to each other. Any unfertilized eggs, or larvae with gross morphological defects (e.g., kinked tails, open brains), which can occur as a result of non-specific damage to eggs during dechorionation, were removed before behavioral assays. Gravitaxis and dimming-response behavioral assays were performed as described previously $[8,10]$, except dishes were always coated with $1 \%$ agarose and larvae were assayed in $0.2 \%$ methyl cellulose in filtered seawater. All larval behavioral assays were performed at $25 \mathrm{~h}$ post-fertilization. For these assays, we waited $5 \mathrm{~min}$ between movies to allow larvae to recover. During all gravitaxis assays, the 505-nm LED was dimmed from 600 to 0 lux and it was positioned above the petri dish [top illumination condition, [8]], shining down onto the dish at a $45^{\circ}$ angle. Movies for gravitaxis assays were recorded for $20 \mathrm{~s}$ prior to the dim and $20 \mathrm{~s}$ post-dim.

To assess the left-right asymmetry of dimmingresponse swim trajectories (i.e., clockwise or counterclockwise), larvae in 6 -cm petri dishes with $0.2 \%$ methyl 
cellulose/seawater were recorded from above with 700$\mathrm{nm}$ illumination and exposed to a 505-nm LED dimmed from 600 or 1500 to 0 lux.

\section{Selection of photo- and gravity-responsive dechorionated larvae}

Dechorionated larvae at 23-24 hpf were placed in a $1 \%$ agarose-coated 6-cm petri dish and observed under a dissection microscope. Room lights were turned off and a fiber optic light source with two stems was used to illuminate the sample dish from the left and right sides. A field of view was chosen containing at least several larvae, taking care to remove any larvae at the air-water interface; if larvae were found at the interface, they were removed with a BSA-coated pipet tip and placed at the bottom of the dish. At intervals of approximately every half minute, the fiber optic light source was dimmed, either by switching off the light at the source or by covering the fiber optic stems with the observer's thumbs or fingers. After $\sim 5 \mathrm{~s}$, light was reintroduced and the field of view was observed. If any larvae were seen swimming upwards toward the surface in response to the dimmed light, they were removed and placed in a separate agarose-coated petri dish for later behavioral assay or for fixation and in situ hybridization (see above). The larvae selected in the upward swimming assay were compared to larvae from the same dish that did not show upward swimming behavior, but were judged to have good overall head-to-tail morphology and a tail-flick response to being touched, as an indication of a functioning motor system. Sibling larvae that were not dechorionated were also kept as controls. The same procedure was followed to find larvae for the swim reversal assay, but after showing upward swimming following dimming, the larvae were sorted by their pigmentation asymmetry, separating those with right-sided ocelli from those with left-sided ocelli. Larvae were placed in a $6-\mathrm{cm} 1 \%$ agarose-coated petri dish containing seawater with MS-222 at $40 \mu \mathrm{g} / \mathrm{mL}$, a concentration at which larvae swam more slowly, allowing for manual sorting by pigmentation asymmetry. Larvae were in the sorting solution at most $5 \mathrm{~min}$, after which time they were transferred to a separate dish with seawater.

\section{Quantification of behavior/statistical analysis}

Behaviors were assayed from at least two different clutches of larvae for each experimental condition, and two or more movies were collected from each clutch. However, we were only able to collect one movie from one of the three non-dechorionated larvae clutches due to an accident in which the petri dish broke after the first movie. Movie editing and behavior analyses were aided with the ImageJ software package. Gravitaxis behavior was evaluated by selecting $\sim 20$ larvae at random from each recording and manually tracking their postdim swims over $20 \mathrm{~s}$, based on previously described criteria [8]. A dim response was qualified as any initiation of swimming immediately following dimming. From each group of recordings for a given condition, the percentages of larvae responding to the dim and swimming in each direction were calculated. Swims were assessed in the $20 \mathrm{~s}$ following dimming and categorized as UP, sideways (SIDE), or DOWN, and the percentage in each category plotted in $90^{\circ}$ wedges (Fig. $7 \mathrm{a}, \mathrm{b}$ ). Swim directions were assigned a value (down $=1$, sideways $=2$, up $=3$ ). Swim speed and tortuosity were calculated using a MATLAB script [10]. Tail beat frequencies (flicks per second) were manually scored using 20-s clips. Comparison of behavioral results between conditions was done as described previously [8], using a Wilcoxon sum rank test (Mann-Whitney $U$ test) to assess statistical significance.

Time-lapse recordings to assess left-right asymmetry of swimming were evaluated by manually tracking the larvae over $13 \mathrm{~s}$ following dimming of the 505 LED lamp, and then scoring the trajectory of each swim as clockwise, counterclockwise, or straight. Each larva was assessed three to five times, with 5-min recovery periods between dimming trials.

\section{Supplementary Information}

The online version contains supplementary material available at https://doi org/10.1186/s12915-021-01075-4.

\section{Additional file 1: Movie S1. Gravitaxis assay for control (no dechorionation), late dechorionated and early dechorionated 25 hour post-fertilization larvae. Movie records 26 seconds of behavior and plays at real time. The light is dimmed at 5.7 seconds (DIM). Circles indicate lar- vae that exemplify the behavior of the group. Up is to the top of the frame for all movies.}

Additional file 2: Movie S2. Dimming response in isolated larvae with normal and reverse left/right asymmetry. The behavior of two larvae are shown for each type. Movie records 26 seconds of behavior and plays at real time. Dimming occurs at 13 seconds (DIM).

Additional file 3: Movie S3. Touch response of larva. The larva is touched with a pipet tip in the area of the posterior apical trunk neurons (pATENs). The movie shows 32 second of behavior and plays in real time.

\section{Acknowledgements}

We acknowledge the use of the NRI-MCDB Microscopy Facility at UC, Santa Barbara. We thank Kerrianne Ryan for her helpful discussions.

Authors' contributions

All authors contributed to the design and conception of this study and participated in the writing and editing of the manuscript. $M B, A Z$, and $M K$ collected and analyzed results; MB and AZ performed statistical analyses, where appropriate. All authors read and approved the final manuscript.

Funding

This work was supported by awards from the NIH (HD038701 and NS103774).

Availability of data and materials

Data generated and analyzed during this study are included in the published article and its additional files. 


\section{Declarations}

Ethics approval and consent to participate

Not applicable.

\section{Consent for publication}

Not applicable.

\section{Competing interests}

The authors declare that they have no competing interests.

\section{Author details}

${ }^{1}$ Neuroscience Research Institute, University of California, Santa Barbara, CA 93106, USA. ${ }^{2}$ College of Creative Studies, University of California, Santa Barbara, CA 93106, USA. ${ }^{3}$ Department of Molecular, Cell and Developmental Biology, University of California, Santa Barbara, CA 93106, USA.

Received: 16 February 2021 Accepted: 17 June 2021 Published online: 13 July 2021

\section{References}

1. Wada H, Saiga $H$, Satoh N, Holland PW. Tripartite organization of the ancestral chordate brain and the antiquity of placodes: insights from ascidian Pax-2/5/8, Hox and Otx genes. Development. 1998;125:1113-22.

2. Manni L, Lane NJ, Joly J-S, Gasparini F, Tiozzo S, Caicci F, et al. Neurogenic and non-neurogenic placodes in ascidians. J Exp Zoolog B Mol Dev Evol. 2004;302:483-504.

3. Abitua PB, Wagner E, Navarrete IA, Levine M. Identification of a rudimentary neural crest in a non-vertebrate chordate. Nature. 2012;492(7427):104-7. https://doi.org/10.1038/nature11589.

4. Abitua PB, Gainous TB, Kaczmarczyk AN, Winchell CJ, Hudson C, Kamata K, et al. The pre-vertebrate origins of neurogenic placodes. Nature. 2015; 524(7566):462-5. https://doi.org/10.1038/nature14657.

5. Stolfi A, Ryan K, Meinertzhagen IA, Christiaen L. Migratory neuronal progenitors arise from the neural plate borders in tunicates. Nature. 2015; 527(7578):371-4. https://doi.org/10.1038/nature15758.

6. Nicol D, Meinertzhagen IA. Cell counts and maps in the larval central nervous system of the ascidian Ciona intestinalis (L.). J Comp Neurol. 1991; 309(4):415-29. https://doi.org/10.1002/cne.903090402.

7. Ryan K, Lu Z, Meinertzhagen IA. The CNS connectome of a tadpole larva of Ciona intestinalis (L.) highlights sidedness in the brain of a chordate sibling. eLife. 2016;5:e16962.

8. Bostwick M, Smith EL, Borba C, Newman-Smith E, Guleria I, Kourakis MJ, et al. Antagonistic inhibitory circuits integrate visual and gravitactic behaviors. Curr Biol. 2020;30(4):600-9. https://doi.org/10.1016/j.cub.2019.12. 017.

9. Salas P, Vinaithirthan V, Newman-Smith E, Kourakis MJ, Smith WC. Photoreceptor specialization and the visuomotor repertoire of the primitive chordate Ciona. J Exp Biol. 2018;221(Pt 7):jeb177972. https://doi.org/10.1242/ jeb.177972.

10. Kourakis MJ, Borba C, Zhang A, Newman-Smith E, Salas P, Manjunath B, et al. Parallel visual circuitry in a basal chordate. eLife. 2019;8:e44753. https:// doi.org/10.7554/eLife.44753.

11. Harada Y, Takagaki Y, Sunagawa M, Saito T, Yamada L, Taniguchi H, et al. Mechanism of self-sterility in a hermaphroditic chordate. Science. 2008; 320(5875):548-50. https://doi.org/10.1126/science.1152488.

12. Lambert CC. Ascidian follicle cells: multifunctional adjuncts to maturation and development. Dev Growth Differ. 2009;51(8):677-86. https://doi.org/1 0.1111/j.1440-169x.2009.01127x.

13. Matsunobu S, Sasakura Y. Time course for tail regression during metamorphosis of the ascidian Ciona intestinalis. Dev Biol. 2015;405(1):7181. https://doi.org/10.1016/j.ydbio.2015.06.016.

14. Satoh N. Developmental biology of ascidians. Cambridge England. New York: Cambridge University Press; 1994

15. Satoh N. Developmental genomics of ascidians. Hoboken: Wiley Blackwell; 2014.

16. Hendrickson C, Christiaen L, Deschet $K$, Jiang D, Joly J-S, Legendre L, et al. Culture of adult ascidians and ascidian genetics. Methods Cell Biol. 2004;74: 143-70. https://doi.org/10.1016/S0091-679X(04)74007-8.

17. Christiaen L, Wagner E, Shi W, Levine M. Isolation of individual cells and tissues from electroporated sea squirt (Ciona) embryos by fluorescence- activated cell sorting (FACS). Cold Spring Harb Protoc. 2009;2009:pdb prot5349.

18. Veeman MT, Chiba S, Smith WC. Ciona genetics. Methods Mol Biol. 2011; 770:401-22. https://doi.org/10.1007/978-1-61779-210-6 15.

19. Boorman CJ, Shimeld SM. Pitx homeobox genes in Ciona and amphioxus show left-right asymmetry is a conserved chordate character and define the ascidian adenohypophysis. Evol Dev. 2002;4(5):354-65. https://doi.org/10.104 6/j.1525-142X.2002.02021.X.

20. Shimeld SM, Levin M. Evidence for the regulation of left-right asymmetry in Ciona intestinalis by ion flux. Dev Dyn. 2006;235(6):1543-53. https://doi. org/10.1002/dvdy.20792.

21. Duboc $V$, Lepage T. A conserved role for the nodal signaling pathway in the establishment of dorso-ventral and left-right axes in deuterostomes. J Exp Zoolog B Mol Dev Evol. 2008;310:41-53.

22. Soukup V, Yong LW, Lu T-M, Huang S-W, Kozmik Z, Yu J-K. The Nodal signaling pathway controls left-right asymmetric development in amphioxus. EvoDevo. 2015;6(1):5. https://doi.org/10.1186/2041-9139-6-5.

23. Hamada $\mathrm{H}$, Tam P. Diversity of left-right symmetry breaking strategy in animals. F1000Res. 2020:9:123. https://doi.org/10.12688/f1000research.21670.1.

24. Tanaka Y, Yamada S, Connop SL, Hashii N, Sawada H, Shih Y, et al. Vitelline membrane proteins promote left-sided nodal expression after neurula rotation in the ascidian. Halocynthia roretzi. Dev Biol. 2019;449(1):52-61. https://doi.org/10.1016/j.ydbio.2019.01.016.

25. Yoshida K, Saiga H. Left-right asymmetric expression of Pitx is regulated by the asymmetric Nodal signaling through an intronic enhancer in Ciona intestinalis. Dev Genes Evol. 2008;218(7):353-60. https://doi.org/10.1007/ s00427-008-0230-3.

26. Yoshida K, Saiga H. Repression of Rx gene on the left side of the sensory vesicle by Nodal signaling is crucial for right-sided formation of the ocellus photoreceptor in the development of Ciona intestinalis. Dev Biol. 2011; 354(1):144-50. https://doi.org/10.1016/j.ydbio.2011.03.006.

27. Kourakis MJ, Smith WC. A conserved role for FGF signaling in chordate otic/ atrial placode formation. Dev Biol. 2007;312(1):245-57. https://doi.org/10.101 6/j.ydbio.2007.09.020.

28. Nishide K, Mugitani M, Kumano G, Nishida H. Neurula rotation determines left-right asymmetry in ascidian tadpole larvae. Dev Camb Engl. 2012;139: 1467-75.

29. Oonuma K, Tanaka M, Nishitsuji K, Kato Y, Shimai K, Kusakabe TG. Revised lineage of larval photoreceptor cells in Ciona reveals archetypal collaboration between neural tube and neural crest in sensory organ formation. Dev Biol. 2016;420(1):178-85. https://doi.org/10.1016/j.ydbio.2016.10.014.

30. Moret F, Christiaen L, Deyts C, Blin M, Vernier P, Joly JS. Regulatory gene expressions in the ascidian ventral sensory vesicle: evolutionary relationships with the vertebrate hypothalamus. Dev Biol. 2005;277(2):567-79. https://doi. org/10.1016/j.ydbio.2004.11.004.

31. Nakane $Y$, Ikegami $K$, ligo $M$, Ono $H$, Takeda $K$, Takahashi $D$, et al. The saccus vasculosus of fish is a sensor of seasonal changes in day length. Nat Commun. 2013;4(1):2108. https://doi.org/10.1038/ncomms3108.

32. Tsuda M, Sakurai D, Goda M. Direct evidence for the role of pigment cells in the brain of ascidian larvae by laser ablation. J Exp Biol. 2003;206(Pt 8):140917. https://doi.org/10.1242/jeb.00235.

33. Jiang D, Tresser JW, Horie T, Tsuda M, Smith WC. Pigmentation in the sensory organs of the ascidian larva is essential for normal behavior. J Exp Biol. 2005;208(Pt 3):433-8. https://doi.org/10.1242/jeb.01420.

34. Sakurai D, Goda M, Kohmura Y, Horie T, Iwamoto H, Ohtsuki H, et al. The role of pigment cells in the brain of ascidian larva. J Comp Neurol. 2004; 475(1):70-82. https://doi.org/10.1002/cne.20142.

35. Horie T, Orii H, Nakagawa M. Structure of ocellus photoreceptors in the ascidian Ciona intestinalis larva as revealed by an anti-arrestin antibody. J Neurobiol. 2005;65(3):241-50. https://doi.org/10.1002/neu.20197.

36. Horie T, Kusakabe T, Tsuda M. Glutamatergic networks in the Ciona intestinalis larva. J Comp Neurol. 2008;508(2):249-63. https://doi.org/10.1 002/cne.21678.

37. Moret F, Christiaen L, Deyts C, Blin M, Joly JS, Vernier P. The dopaminesynthesizing cells in the swimming larva of the tunicate Ciona intestinalis are located only in the hypothalamus-related domain of the sensory vesicle. Eur J Neurosci. 2005;21(11):3043-55. https://doi.org/10.1111/j.1460-9568.2 005.04147.x.

38. Ryan K, Lu Z, Meinertzhagen IA. The peripheral nervous system of the ascidian tadpole larva: types of neurons and their synaptic networks. $J$ Comp Neurol. 2018;526(4):583-608. https://doi.org/10.1002/cne.24353. 
39. Christiaen L, Burighel P, Smith WC, Vernier P, Bourrat F, Joly J-S. Pitx genes in Tunicates provide new molecular insight into the evolutionary origin of pituitary. Gene. 2002;287(1-2):107-13. https://doi.org/10.1016/50378-1119(01 )00865-4.

40. Morokuma J, Ueno M, Kawanishi H, Saiga H, Nishida H. HrNodal, the ascidian nodal-related gene, is expressed in the left side of the epidermis, and lies upstream of HrPitx. Dev Genes Evol. 2002;212(9):439-46. https://doi. org/10.1007/s00427-002-0242-3.

41. Christiaen L, Bourrat F, Joly J-S. A modular cis-regulatory system controls isoform-specific pitx expression in ascidian stomodæum. Dev Biol. 2005; 277(2):557-66. https://doi.org/10.1016/j.ydbio.2004.10.008.

42. Lowe EK, Stolfi A. Developmental system drift in motor ganglion patterning between distantly related tunicates. EvoDevo. 2018;9(1):18. https://doi.org/1 0.1186/s13227-018-0107-0.

43. Gibboney S, Orvis J, Kim K, Johnson CJ, Martinez-Feduchi P, Lowe EK, et al. Effector gene expression underlying neuron subtype-specific traits in the motor ganglion of Ciona. Dev Biol. 2020;458(1):52-63. https://doi.org/10.101 6/j.ydbio.2019.10.012.

44. Sato Y, Terakado K, Morisawa M. Test cell migration and tunic formation during post-hatching development of the larva of the ascidian, Ciona intestinalis. Dev Growth Differ. 1997;39(1):117-26. https://doi.org/10.1046/ j.1440-169X.1997.00013.X

45. Sato $Y$, Morisawa M. Loss of test cells leads to the formation of new tunic surface cells and abnormal metamorphosis in larvae of Ciona intestinalis (Chordata, ascidiacea). Dev Genes Evol. 1999;209(10):592-600. https://doi. org/10.1007/s004270050293.

46. Levin M. Left-right asymmetry in embryonic development: a comprehensive review. Mech Dev. 2005;122(1):3-25. https://doi.org/10.1016/ j.mod.2004.08.006.

47. Güntürkün O, Ströckens F, Ocklenburg S. Brain lateralization: a comparative perspective. Physiol Rev. 2020;100(3):1019-63. https://doi.org/10.1152/ physrev.00006.2019.

48. Miletto Petrazzini ME, Sovrano VA, Vallortigara G, Messina A. Brain and behavioral asymmetry: a lesson from fish. Front Neuroanat. 2020;14:11. https://doi.org/10.3389/fnana.2020.00011.

49. Horstick EJ, Bayleyen Y, Burgess HA. Molecular and cellular determinants of motor asymmetry in zebrafish. Nat Commun. 2020;11(1):1170. https://doi. org/10.1038/s41467-020-14965-y.

50. Barth KA, Miklosi A, Watkins J, Bianco IH, Wilson SW, Andrew RJ. fsi zebrafish show concordant reversal of laterality of viscera, neuroanatomy, and a subset of behavioral responses. Curr Biol. 2005;15(9):844-50. https://doi. org/10.1016/j.cub.2005.03.047

51. Christiaen L, Wagner E, Shi W, Levine M. Isolation of sea squirt (Ciona) gametes, fertilization, dechorionation, and development. Cold Spring Harb Protoc. 2009;2009:pdb prot5344.

52. Hotta K, Mitsuhara K, Takahashi H, Inaba K, Oka K, Gojobori T, et al. A webbased interactive developmental table for the ascidian Ciona intestinalis, including 3D real-image embryo reconstructions: I. From fertilized egg to hatching larva. Dev Dyn. 2007;236(7):1790-805. https://doi.org/10.1002/ dvdy.21188.

\section{Publisher's Note}

Springer Nature remains neutral with regard to jurisdictional claims in published maps and institutional affiliations.

Ready to submit your research? Choose BMC and benefit from:

- fast, convenient online submission

- thorough peer review by experienced researchers in your field

- rapid publication on acceptance

- support for research data, including large and complex data types

- gold Open Access which fosters wider collaboration and increased citations

- maximum visibility for your research: over $100 \mathrm{M}$ website views per year

At BMC, research is always in progress.

Learn more biomedcentral.com/submissions 